\title{
ANALISIS AKTOR POPULAR DAN SUTRADARA BERPENGARUH BERDASARKAN DATA DBPEDIA MENGGUNAKAN ALGORITMA CLOSENESS CENTRALITY DAN NODE2VEC
}

\author{
KARIMA MUFIDAH ${ }^{1}$, NOVYANT SYAHPUTRA ${ }^{2}$, NUR AINI RAKHMAWATI ${ }^{3}$ \\ Institut Teknologi Sepuluh Nopember 123 \\ e-mail : karimamufidah@gmail.com
}

\begin{abstract}
The rapid development of web technology makes it easier for humans to access various information. The third generation of web-based internet services (Web 3.0) has introduced the Semantic Web which aims to enable content on the web to be understood by computers. The application of semantic web can be done to retrieve a dataset from Dbpedia Indonesia, which is a list of Indonesian films, for further data analysis. The purpose of data analysis is to find out the most popular actors and directors in the Indonesian film industry. This study uses closeness centrality and Node2vec algorithms to determine the level of popularity of actors. In addition, this study also uses density graph to determine the influential directors in the Indonesian film industry. The results of the algorithm calculations are visualized using Neo4j, Networkx, and tSNE which are graphs. In this study it was found that Rima Melati was the most popular actor because of the highest closeness centrality value. This can also be interpreted that Rima Melati is an actor who starred in the most films. While in density graph calculation, Sophan Sophiaan is the most influential director because he directs the most movie titles.
\end{abstract}

Key Words : closeness centrality, dbpedia, density graph, networkx, node2vec

\section{ABSTRAK}

Perkembangan teknologi web yang semakin pesat membuat manusia semakin mudah dalam mengakses berbagai informasi. Generasi ketiga dari layanan internet berbasis web (Web 3.0) telah memperkenalkan Semantic Web yang bertujuan untuk memungkinakan konten pada web agar dapat dipahami oleh komputer. Penerapan Semantic Web dapat dilakukan untuk mengambil dataset dari DBpedia Indonesia, yaitu daftar film Indonesia, untuk selanjutnya dilakukan analisis data. Tujuan analisis data adalah untuk mengetahui aktor dan sutradara terpopuler dalam industri perfilman Indonesia. Penelitian ini menggunakan algoritma closeness centrality dan Node2vec untuk menentukan tingkat popularitas aktor. Selain itu, penelitian ini juga menggunakan density graph untuk mengetahui sutradara yang berpengaruh di industri perfilman Indonesia. Hasil dari perhitungan algoritma tersebut divisualisasikan menggunakan Neo4j, Networkx dan tSNE yang mana berupa graf. Pada penelitian ini ditemukan bahwa Rima Melati merupakan aktor terpopuler karena nilai closeness centralitynya tertinggi. Hal ini juga dapat diartikan bahwa Rima Melati merupakan aktor yang membintangi judul film terbanyak. Sedangkan pada perhitungan density graph, Sophan Sophiaan merupakan sutradara yang paling berpengaruh karena menyutradarai paling banyak judul film.

Kata Kunci: closeness centrality, dbpedia, density graph, networkx, node2vec 


\section{PENDAHULUAN}

Internet telah menjadi sarana untuk mempermudah setiap orang mengakses segala bentuk pengetahuan dan informasi. Hal ini dimungkinkan karena adanya perkembangan teknologi web dari tahun ke tahun [1]. Pada tahun 2002, Tim BernersLee mencetuskan teknologi web terbaru yaitu Semantic Web yang dinamai dengan era Web 3.0. Hadirnya semantic web bertujuan untuk memperkaya informasi yang diberikan sehingga menjadi lebih baik dalam pendefinisiannya, agar memungkinkan komputer dapat memahami informasi yang tekah diberikan sehingga komputer dan manusia dapat bekerja sama [2]. Cara kerja semantic web adalah dengan mengambil URI (Uniform Resource Identifier) pada sebuah web.

Pengaplikasian semantic web dapat dilakukan untuk pengambilan data pada DBpedia Indonesia. DBpedia merupakan sebuah komunitas yang bergerak untuk mengekstrak informasi terstruktur dari Wikipedia, dalam hal ini merupakan Wikipedia Indonesia, dan menyediakan informasi tersebut dalam sebuah web [1]. Untuk mengakses pengetahuan (knowledge) DBpedia, digunakan URI resource dari entitas dalam bentuk SPARQL.

Adapun beberapa penelitian sebelumnya yang terkait dengan penelitian ini yaitu Adang Rochiyat dan Arief Wibowo yang melalukan analisis aktor berpengaruh dan aktor popular dengan metode degree centrality dan follower rank dengan dataset berasal dari tagar Twitter \#gejayanmemanggil [3]. Dari penelitian tersebut diketahui bahwa aktor Ryan Restu merupakan aktor yang berpengaruh karena memiliki nilai degree centrality tertinggi dan aktor Tirto ID merupakan aktor yang paling popular karena memiliki nilai follower rank yang tertinggi. Selain itu, beberapa penelitian sebelumnya [4] [5] [6] [7] juga telah membuktikan bahwa dengan menggunakan algoritma closeness centrality dapat menunjukkan nilai sentralitas yang berfungsi untuk mengetahui tingkat popularitas dan pengaruh node (aktor) pada sebuah jaringan.

Pada penelitian ini, data yang diambil pada DBpedia Indonesia adalah daftar film Indonesia yang nantinya akan dilakukan analisis data. Tujuan dari analisis data adalah untuk mengetahui aktor dan sutradara terpopuler dalam industri perfilman Indonesia. Selain itu, analisis ini juga bertujuan untuk mengetahui siapa tokoh (aktor/sutradara) yang berpengaruh di industri tersebut. Metode yang digunakan adalah algoritma closeness centrality dan Node2vec untuk mengetahui tingkat popularitas artis dan sutradara. Hasil perhitungan algoritma tersebut divisualisasikan dengan Neo4j, Networkx, dan tSNE yang mana berupa graph. Penelitian ini diharapkan dapat memberikan wawasan dan pengetahuan baru kepada masyarakat dan pengamat film mengenai aktor dan sutradara yang memiliki pengaruh di industri perfilman Indonesia.

\section{TINJAUAN PUSTAKA}

Penelitian ini menggunakan dasar teori yang menjadi acuan selama pengerjaan sehingga dapat lebih sistematis.

\section{SPARQL}

Simple Protocol and RDF Query Language atau lebih dikenal dengan SPARQL adalah bahasa yang digunakan untuk melakukan query data dalam semantic web [8]. Dengan adanya SPARQL, masingmasing sumber data dapat terhubung satu sama lain. Dalam penggunaanya, query SPARQL memiliki struktur yang umumnya digunakan seperti contoh yang ditunjukkan pada Gambar 1.

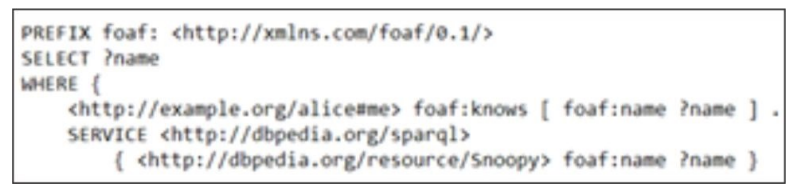

Gambar 1. Struktur Query SPARQL

Gambar 1 menunjukkan bahwa umumnya pada query SPARQL terdapat PREFIX, SELECT, dan WHERE. PREFIX berfungsi untuk mempersingkat penulisan alamat data sehingga penulisan query dapat dilakukan lebih mudah. SELECT berfungsi untuk mengambil data dari SPARQL endpoint dan hasilnya berupa tabel, sedangkan WHERE merupakan syarat atau permintaan yang telah ditentukan. Pada contoh tersebut, output yag dihasilkan berupa nama dari dbpedia resource yang digunakan, yaitu Snoopy, yang ditunjukkan pada Gambar 2.

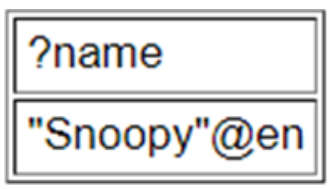

Gambar 2. Contoh Output Query SPARQL

\section{Node2vec}

Node2vec merupakan sebuah algoritma framework yang berfungsi untuk memetakan node ke dalam bentuk vector pada sebuah jaringan [9]. Dengan memilih satu titik/node yang tepat pada lingkungan sekitarnya (jaringan), Node2vec dapat mempelajari representasi yang mengatur node berdasarkan pada peran jaringan atau komunitas tempat node tersebut bergabung.

Node2vec memiliki parameter $p$ dan $q$ yang berfungsi untuk menampilkan variabel bias random walks. Parameter $p$ atau disebut juga dengan return parameter berfungsi untuk mengontrol kemung- 
kinan perjalanan kembali sebuah node dalam jaringannya. Sedangkan parameter $q$ atau disebut juga dengan in-out parameter berfungsi memungkinkan sebuah node melakukan pencarian untuk membedakan antara node ke dalam (inward) dan ke luar (outward).

\section{Closeness Centrality}

Closeness centrality merupakan algoritma yang berfungsi untuk menghitung jarak rata-rata node dengan semua node lain dalam suatu jaringan [10]. Ukuran ini menggambarkan kedekatan satu node dengan node yang lain dalam suatu jaringan. Semakin besar nilai closeness centrality yang dimiliki menandakan bahwa node tersebut memiliki tingkat eksistensi paling tinggi diantara node yang lain. Gambar 3 menunjukkan contoh graf closeness centrality.

Dari contoh graf yang ditunjukkan oleh Gambar 3, nilai closeness centrality tertinggi dimiliki oleh Wulan karena menghubungkan banyak node dalam jaringan.

Untuk menghitung nilai closeness centrality pada sebuah node dapat menggunakan rumus (1) berikut.

$$
C(u)=\frac{n-1}{\sum_{v=1}^{n-1} d(u, v)} \quad \ldots . .(1)
$$

Pada rumus tersebut, $u$ melambangkan sebuah node, $n$ merupakan jumlah node dalam komponen yang sama (subgraph atau graph) seperti $u$, sedangkan $d(u, v)$ adalah jarak jalur terpendek antara node $v$ dan node $(u)$ lainnya.

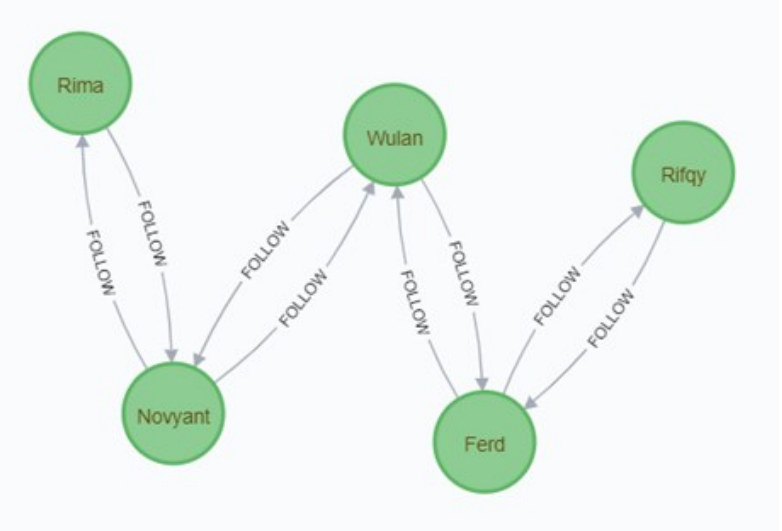

Gambar 3. Contoh Graf Closeness Centrality

\section{Neo4j}

Neo4j merupakan graph database yang diperkenalkan pada tahun 2007. Pada Neo4j, graf memiliki properti yang terdiri dari node, relationship, direction, dan label [11]. Node merupakan aktor yang memiliki peran dalam jaringan, relationship merupakan hubungan yang dimiliki antar node, direction merupakan arah hubungan dari node satu ke node yang lain, sedangkan label digunakan untuk memberi nama pada node dan relationship.

\section{Networkx}

Networkx adalah salah satu package pada bahasa pemrograman Python yang berfungsi untuk mengeksplorasi dan menganalisis jaringan dan algoritma jaringan [12]. Networkx menyediakan berbagai jenis graf untuk menggambarkan jaringan, termasuk simple graph dan directed graph. Beberapa contoh algoritma graf yang dapat diimplementasikan dengan Networkx adalah shortest paths, betweenness centrality, closeness centrality, dan lain sebagainya.

\section{t-SNE}

t-SNE juga merupakan salah satu package pada Python yang berfungsi untuk membuat visualisasi data [13]. Dengan t-SNE, visualisasi yang dihasilkan jauh lebih baik karena algoritma ini mengurangi kecenderungan titik kerumunan di tengah peta. t-SNE lebih baik daripada teknik yang ada saat membuat peta tunggal (single map) yang mengungkapkan struktur pada banyak skala yang berbeda.

\section{Density Graph}

Density didefinisikan sebagai rasio antara edge (tepi) dan node (simpul) dari sebuah subgraph atau rata-rata degree (node yang terhubung) dibagi 2 [14]. Dengan density graph dapat diketahui jarak antara node satu dengan yang lain. Density graph juga dapat menentukan node mana yang memiliki pengaruh terbesar dalam sebuah jaringan. 


\section{METODE}

Penelitian ini dilakukan sesuai dengan alur yang ditunjukkan pada Gambar 4. Tahapan pada alur tersebut meliputi query SPARQL, pemodelan graph, perhitungan algoritma closeness centrality dan Node2vec, dan yang terakhir adalah visualisasi hasil dari algoritma tersebut.

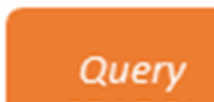

SPARQL
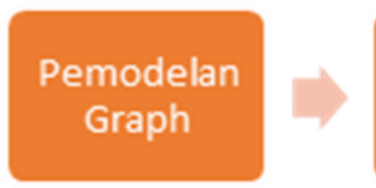
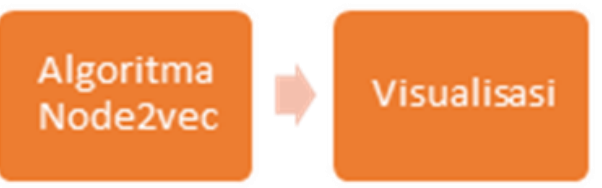

Gambar 4. Alur Metode Penelitian

\section{Query SPARQL}

Query yang digunakan untuk mendapatkan data daftar film dari DBpedia Indonesia [15], digunakan property wikiPageWikiLink yang dituliskan dengan dbpedia-owl:wikiPageWikiLink. Untuk mengambil data sutradara digunakan property director yang dituliskan dengan dbpedia-owl:starring. Detil dari query adalah sebagai berikut:

SELECT ?film ?labelFilm ?director ? labelDirector ?starring ?labelStarring WHERE \{

<http://id.dbpedia.org/resource/

Daftar_film_Indonesia> dbpedia-

owl:wikiPageWikiLink ?film.

?film rdfs:label ?labelFilm.

?film dbpedia-owl:director ?director.

?director rdfs:label ?labelDirector.

?film dbpedia-owl:starring ?starring.

?starring rdfs:label ?labelStarring. \}

Data yang dihasilkan dari query tersebut kemudian disimpan dalam format CSV. Tabel 1 merupakan sampel data hasil query.
Tabel 1. Sampel Data Hasil Query

\begin{tabular}{|c|c|c|c|}
\hline No & Film & Sutradara & Aktor \\
\hline 1. & $\begin{array}{l}\text { Pengkhianatan G } \\
30 \mathrm{~S} / \mathrm{PKI}\end{array}$ & $\begin{array}{ll}\text { Arifin } & \text { C. } \\
\text { Noer } & \end{array}$ & $\begin{array}{l}\text { Umar } \\
\text { Kayam }\end{array}$ \\
\hline 2. & $\begin{array}{l}\text { Pengkhianatan G } \\
30 \mathrm{~S} / \mathrm{PKI}\end{array}$ & $\begin{array}{ll}\text { Arifin } & \text { C. } \\
\text { Noer } & \end{array}$ & Ade Irawan \\
\hline 3. & $\begin{array}{l}\text { Pengkhianatan G } \\
30 \mathrm{~S} / \mathrm{PKI}\end{array}$ & $\begin{array}{ll}\text { Arifin } & \text { C. } \\
\text { Noer } & \end{array}$ & Sofia WD \\
\hline 4. & Taksi (film) & $\begin{array}{ll}\text { Arifin } & \text { C. } \\
\text { Noer } & \end{array}$ & $\begin{array}{l}\text { Rano Kar- } \\
\text { no }\end{array}$ \\
\hline 5. & Taksi (film) & $\begin{array}{ll}\text { Arifin } & \text { C. } \\
\text { Noer } & \end{array}$ & $\begin{array}{l}\text { Meriam } \\
\text { Bellina }\end{array}$ \\
\hline
\end{tabular}

Dari query SPARQL yang telah dijalankan, dihasilkan sejumlah 3874 baris data yang terdiri dari 3 kolom, yaitu film, sutradara, dan pemain (aktor). Statistic jumlah proporsi data ditunjukkan oleh tabel 2. Data tersebut disimpan pada repositori Github yang terhubung dengan Zenodo [16]. Data ini dihasilkan pada saat query bulan Mei 2020.

Tabel 2. Statistik Jumlah Data

\begin{tabular}{|l|r|}
\hline \multicolumn{1}{|c|}{ Node } & \multicolumn{1}{c|}{ Jumlah } \\
\hline Judul Film & 611 \\
\hline Sutradara & 152 \\
\hline Pemain & 1006 \\
\hline
\end{tabular}




\section{Pemodelan Graph}

Setelah data didapatkan menggunakan query SPARQL selanjutnya dilakukan pemodelan graph. Pemodelan graph merupakan proses mengubah bentuk data yang awalnya berbasis tabel menjadi graf. Graf yang akan dibuat memiliki 3 jenis node yang berasa dari 3 kolom pada Tabel 1 , yaitu node judul film, sutradara, dan aktor. Proses ini dilakukan dengan menggunakan aplikasi Neo4j. Dengan adanya pemodelan graf dapat diketahui network yang terbentuk dari node-node di dalamnya.

\section{Menjalankan Node2vec}

Algoritma Node2vec akan dijalankan dengan bahasa pemrograman Python menggunakan aplikasi Jupyter Notebook untuk menghasilkan angka perplexity dan visualisasi dari graf. Node yang digunakan dalam algoritma ini adalah judul film dengan parameter 'film', nama sutradara dengan parameter 'sutradara', dan nama aktor dengan parameter 'pemain'.

\section{Algoritma Closeness Centrality}

Algoritma closeness centrality akan dijalankan pada aplikasi Neo4j. Pada algoritma ini terdapat beberapa parameter yang digunakan dalam penelitian, Nama dan fungsi dari parameter ditunjukkan pada Tabel 3.

Tabel 3. Parameter yang Digunakan

\begin{tabular}{|l|l|l|}
\hline \multicolumn{1}{|c|}{ Nama } & Tipe & \multicolumn{1}{|c|}{ Fungsi } \\
\hline Label & String & $\begin{array}{l}\text { Memberi label pada } \\
\text { node graf }\end{array}$ \\
\hline $\begin{array}{l}\text { Relation- } \\
\text { ship }\end{array}$ & String & $\begin{array}{l}\text { Memberi relasi antar } \\
\text { node pada graf }\end{array}$ \\
\hline Concurency & Integer & $\begin{array}{l}\text { Menjalankan algoritma } \\
\text { yang diinginkan }\end{array}$ \\
\hline Graph & String & $\begin{array}{l}\text { Menampilkan graf } \\
\text { dengan label dan rela- } \\
\text { tionship }\end{array}$ \\
\hline
\end{tabular}

\section{Visualisasi}

Setelah melakukan perhitungan algoritma, hasil yang diperoleh akan divisualisasikan menggunakan bahasa pemrograman Python dengan library Networkx dan t-SNE. Melalui visualisasi ini dapat diketahui lebih jelas siapa aktor dan sutradara yang popular dan berpengaruh.

\section{HASIL DAN PEMBAHASAN}

\section{Pemodelan Graph menggunakan Neo4j}

Untuk membuat pemodelan graf dari data daftar film Indonesia yang telah didapatkan harus dilakukan pemisahan data sutradara pada tabel sebelumnya dan digantikan oleh id sutradara. Pemberian id pada sutradara harus dilakukan agar tidak ada data yang terduplikasi pada saat membuat model graf. Setelah itu data dapat diimpor ke aplikasi Neo4j. Gambar 5 menunjukkan pemodelan graf yang dihasilkan dengan pemberian warna yang berbeda berdasarkan atribut node. Atribut judul film menggunakan warna merah muda, atribut aktor menggunakan warna biru, dan untuk atribut sutradara menggunakan warna kuning. Begitu juga dengan jenis relationship-nya. Jenis relationship antara judul film dan sutradara pada graf tersebut adalah MADE_BY (dibuat oleh), sedangkan jenis relationship antara judul film dan aktor pada graf adalah PLAYED_BY (dibintangi oleh).

\section{Perhitungan Algoritma Closeness Centrality}

Saat perhitungan algoritma closeness centrality, node yang digunakan merupakan node aktor karena tujuannya adalah untuk mengetahui siapa aktor yang paling popular. Perhitungan ini juga dilakukan menggunakan aplikasi Neo4j. Hasil nilai closeness centrality dapat dilihat pada Tabel 4.

Tabel 4. Nilai Closeness Centrality pada Node

\begin{tabular}{|l|l|}
\hline \multicolumn{1}{|c|}{ Node (Aktor) } & \multicolumn{1}{c|}{ Closeness Centrality } \\
\hline Rima Melati & 0.2593026662760035 \\
\hline Rina Hasyim & 0.2546029919447641 \\
\hline Nani Widjaja & 0.2523524379811805 \\
\hline Rachmat Hidayat & 0.25134904856574836 \\
\hline$\ldots$ & $\ldots$ \\
\hline $\begin{array}{l}\text { lqbaal Dhiafakhri } \\
\text { Ramadhan }\end{array}$ & 0.13445761166818596 \\
\hline $\begin{array}{l}\text { Teuku Rizky Mu- } \\
\text { hammad }\end{array}$ & 0.13445761166818596 \\
\hline $\begin{array}{l}\text { Bastian Bintang } \\
\text { Simbolon }\end{array}$ & 0.13445761166818596 \\
\hline Fachri Albar & 0.13248502994011976 \\
\hline
\end{tabular}




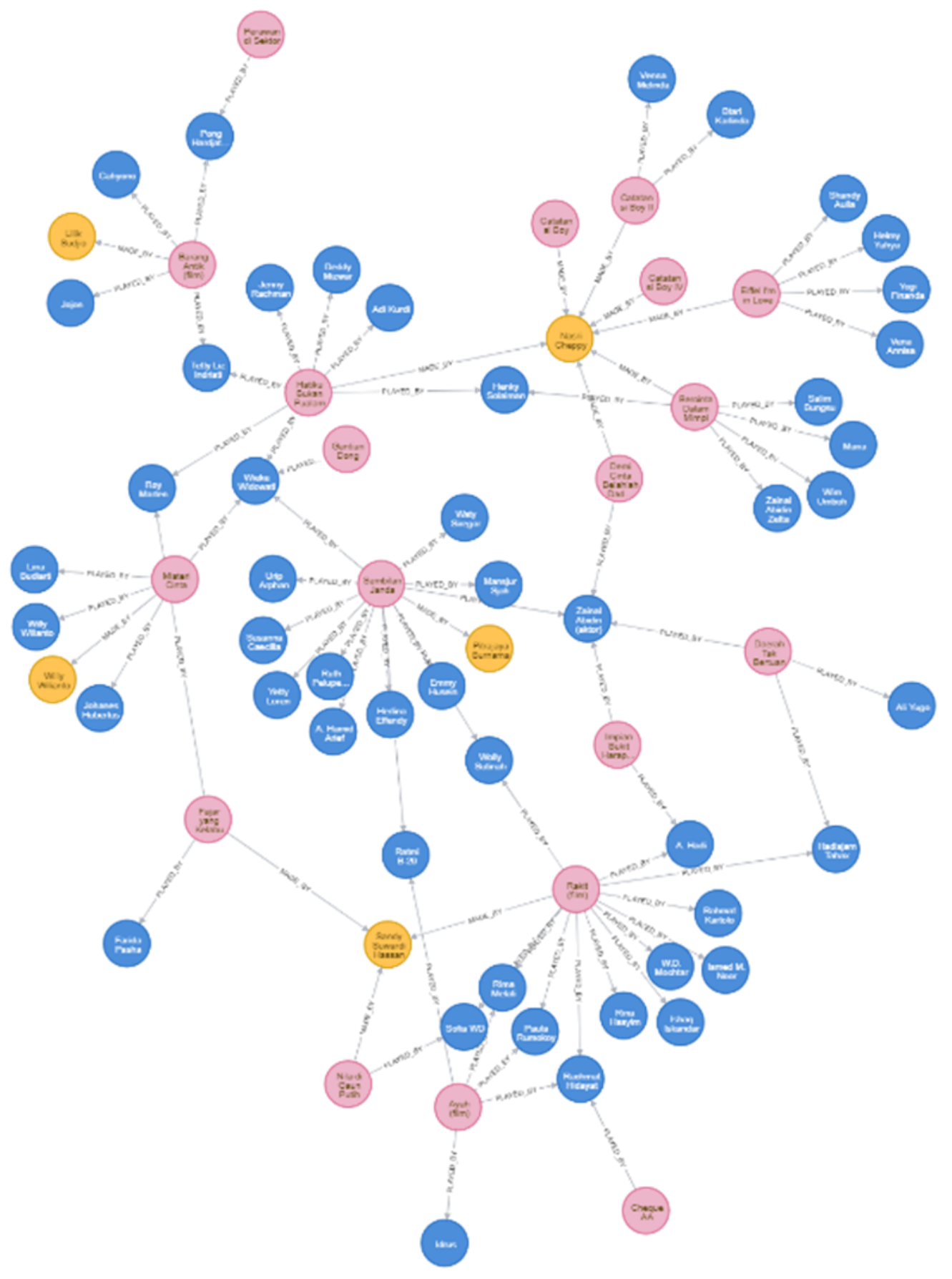

Gambar 5. Pemodelan Graf

Berdasarkan Tabel 4 didapatkan urutan node dengan nilai closeness centrality mulai dari yang tertinggi hingga yang terendah. Nilai tertinggi dimiliki oleh aktor Rima Melati dengan nilai 0.259, hal ini dapat diartikan bahwa aktor Rima Melati yang ada pada dataset ini paling banyak memain kan judul film. Sedangkan nilai closeness centrality terendah dimiliki oleh aktor Fachri Albar dengan nilai 0.132 yang juga dapat diartikan bahwa aktor Fachri Albar memainkan paling sedikit judul film. 


\section{Perhitungan Algoritma Node2vec}

Sebelum diproses, data yang akan dijadikan node dibentuk menjadi sebuah graf terlebih dahulu dengan library Networkx. Setelah itu algoritma Node2vec dijalankan dengan parameter dimension sebesar 20, walk_length sebesar 16, num_walks sebesar 100 dan Workers sebesar 2.

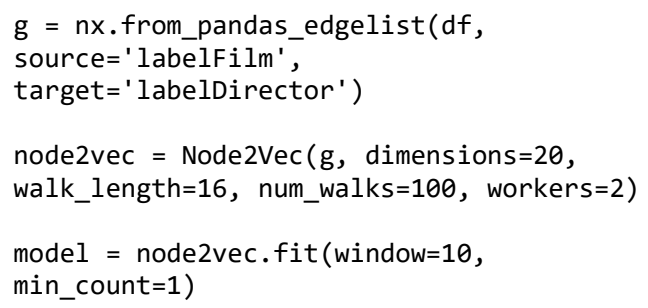

Gambar 6. Mengubah Data Menjadi Graf dengan Neode2vec
Untuk analisa lebih lanjut, digunakan visualisasi dengan library Networkx pada Python, pada visualisasi ini dapat dilihat aktor populer atau banyak bermain pada sebuah judul film dan sutradara yang populer atau banyak menyutradarai judul film. Hasil dari kode tersebut ditunjukkan pada Gambar 7 dengan node berwarna oranye menunjukkan aktor yang memainkan 2 atau lebih relasi dengan node lainnya. Kemudian node yang berwarna hijau merupakan sutradara film yang memiliki 2 atau lebih relasi dengan node lain.

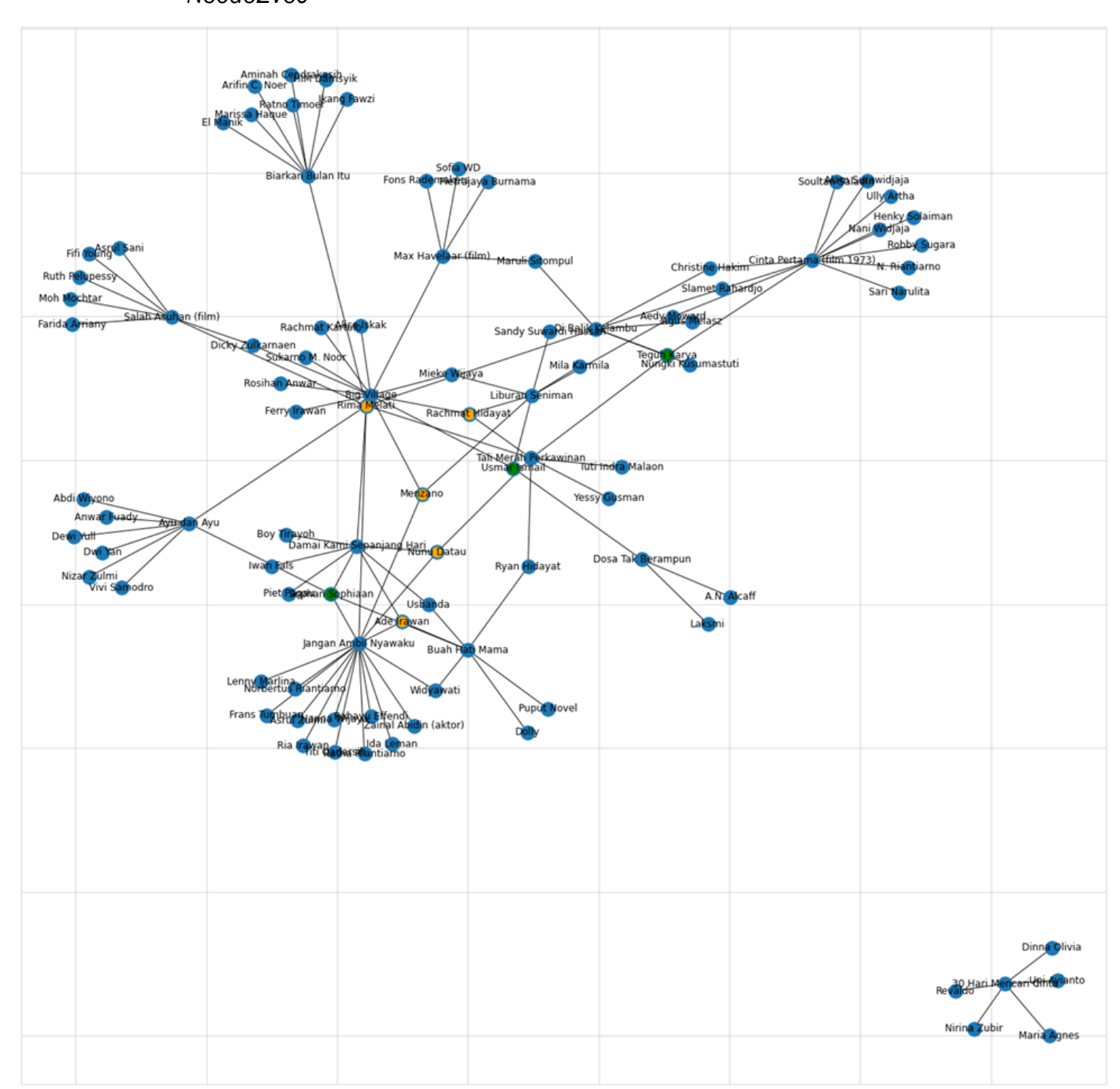

Gambar 7. Visualisasi Menggunakan Networkx 
Dari Gambar 7 dapat diketahui bahwa Rima Melati merupakan aktor popular karena nodenya berwarna kuning. Hal ini juga sesuai dengan hasil perhitungan closeness centrality yang mana Rima Melati juga memiliki nilai tertinggi yang menandakan aktor tersebut popular. Untuk sutradara, Sophan Sophiaan merupakan sutradara berpengaruh karena menyutradarai paling banyak film. Hal ini sesuai dengan warna node Sophan Sophiaan pada graf yang berwarna hijau.

\section{Visualisasi Data dengan t-SNE}

Pada visualisasi data menggunakan t-SNE, nantinya dapat dilihat hubungan antar node. Parameter yang digunakan pada penelitian yaitu n_components $=2$ yaitu labelDirector dan labelStarring, random_state $=7$ dan perplexity $=15$. tsne $=$ TSNE $\left(n_{-}\right.$components $=2$,

random_state $=\overline{7}$, perplexity $=15$ )

embeddings_2d = tsne.fit_transform

Gambar 8. Baris Kode Visualisasi t-SNE

Legend yang digunakan pada visualisasi tSNE sutradara terhadap judul film adalah nama sutradara film yang diberi tanda dengan beberapa warna yang berbeda dan node nama film divisualisasikan dalam bentuk scatter plot dimana titik-titik dengan label nama film merupakan representasi judul film yang disutradarai oleh sutradara film. Grafik scatter plot ini berguna untuk mengetahui persebaran judul film dengan sutradara tertentu. Sehingga, dapat ditarik kesimpulan sutradara Sophan Sophiaan menyutradarai judul film paling banyak dan sutradara Arifin C. Noer memiliki menyutradarai judul film paling sedikit.

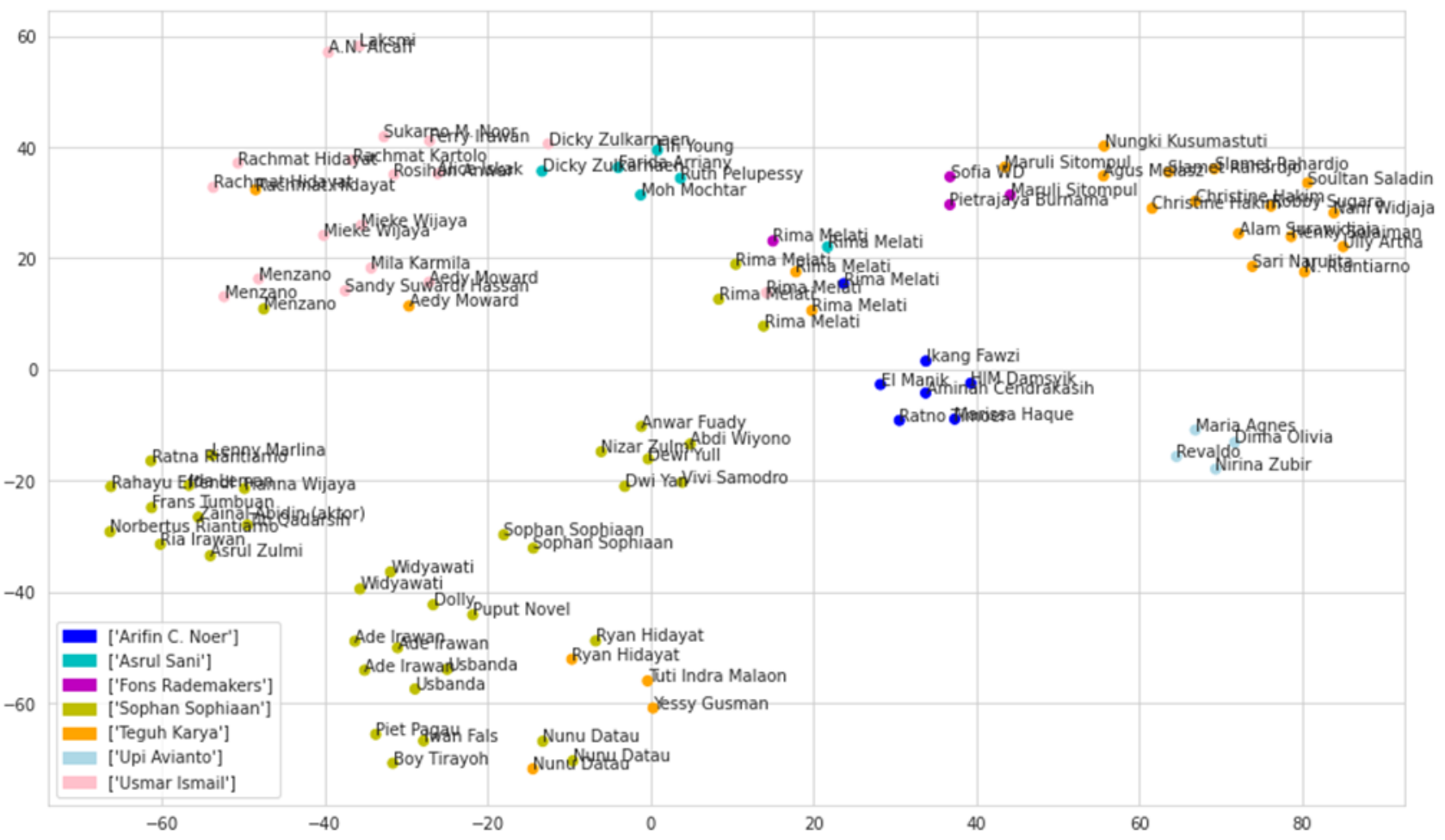

Gambar 9. Visualisasi t-SNE Sutradara Terhadap Judul Film 
Selanjutnya, pada Gambar 10 menunjukkan visualisasi aktor terhadap judul film. Legend yang digunakan pada visualisasi ini adalah Judul film yang diberi tanda dengan beberapa warna berbeda berbeda dan node nama aktor divisualisasikan dalam bentuk scatter plot. Grafik scatter plot ini berguna untuk mengetahui persebaran aktor dengan judul film tertentu. Berdasarkan Gambar 10 dapat dilihat bahwa judul film yang dimainkan oleh aktor Rima Melati merupakan yang terbanyak. Hal ini juga mendukung pernyataan hasil perhitungan yang telah dilakukan sebelumnya yang menyatakan bahwa Rima Melati merupakan aktor yang paling popular.

\section{Perhitungan dan Visualisasi dengan Density Graph}

Pada Gambar 11 menunjukkan degree graph dimana semakin besar node nya maka semakin besar degree nya. Node yang memiliki ukuran terbesar adalah node judul film Jangan Ambil Nyawaku yang menandakan bahwa di film tersebut banyak melibatkan aktor. Namun dalam penelitian ini yang ingin diketahui adalah aktor dan sutradara yang berpengaruh. Sehingga jika dilihat dengan atribut aktor, Rima Melati memiliki ukuran node terbesar dibandingkan dengan aktor-aktor lainnya. Sedangkan jika dilihat dengan atribut sutradara, Sophan Sophiaan juga memiliki ukuran node terbesar dibandingkan dengan sutradara lainnya. Hasil yang diperoleh dengan density graph semakin memperkuat hasil perhitungan yang dilakukan sebelumnya.

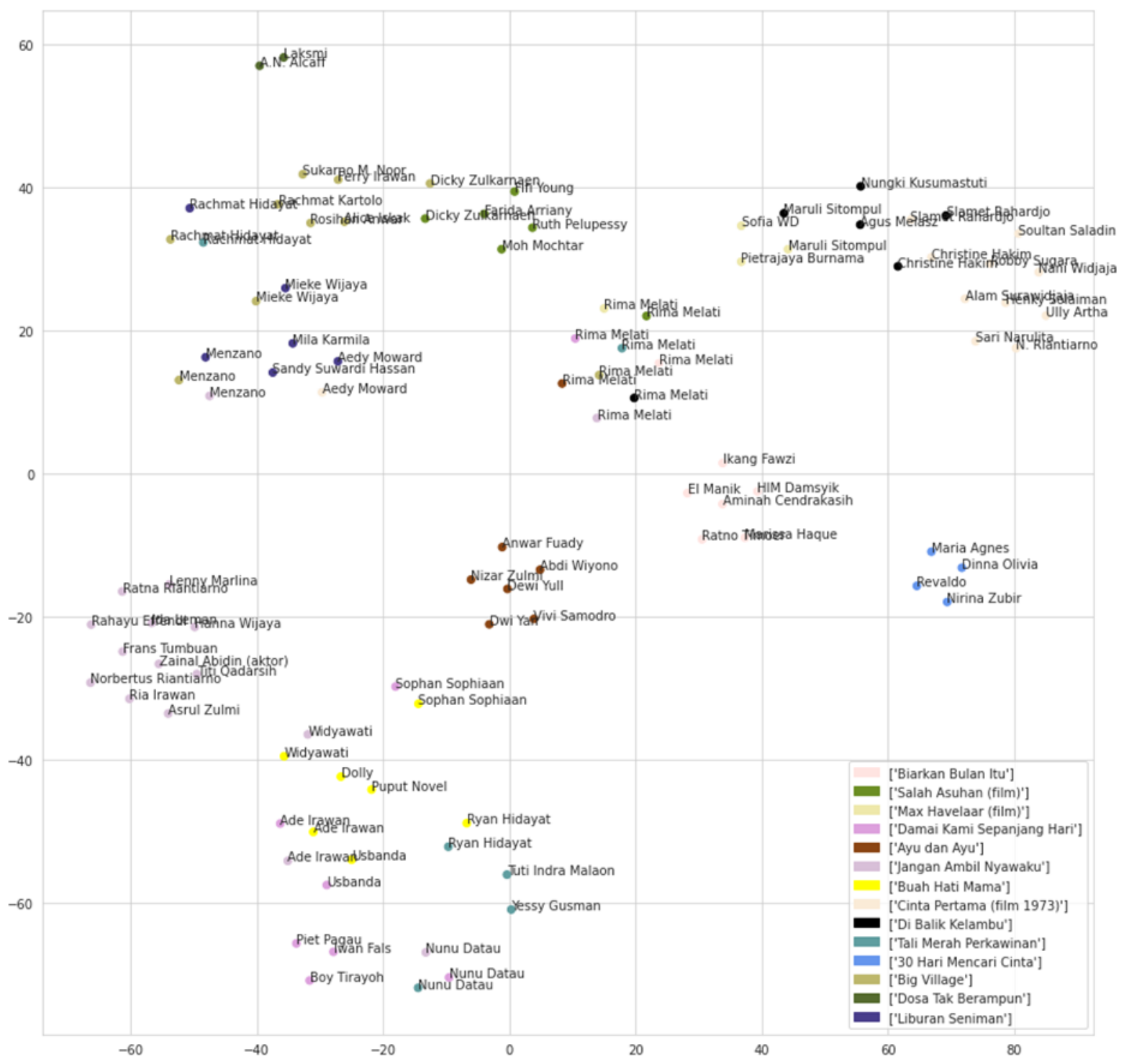

Gambar 10. Visualisasi t-SNE Aktor Terhadap Judul Film 


\section{KESIMPULAN}

Berdasarkan hasil nilai closeness centrality, Networkx, t-SNE, dan density graph dapat ditarik kesimpulan bahwa Rima Melati merupakan aktor yang paling popular dalam industri perfilman Indone- sia. Tingkat popularitas Rima Melati ditunjukkan dengan banyaknya judul film yang ia bintangi. Sedangkan untuk sutradara berpengaruh dalam industri perfilman Indonesia jatuh kepada Sophan Sophiaan. hal ini dibuktikan dengan banyaknya judul film yang disutradarai olehnya.

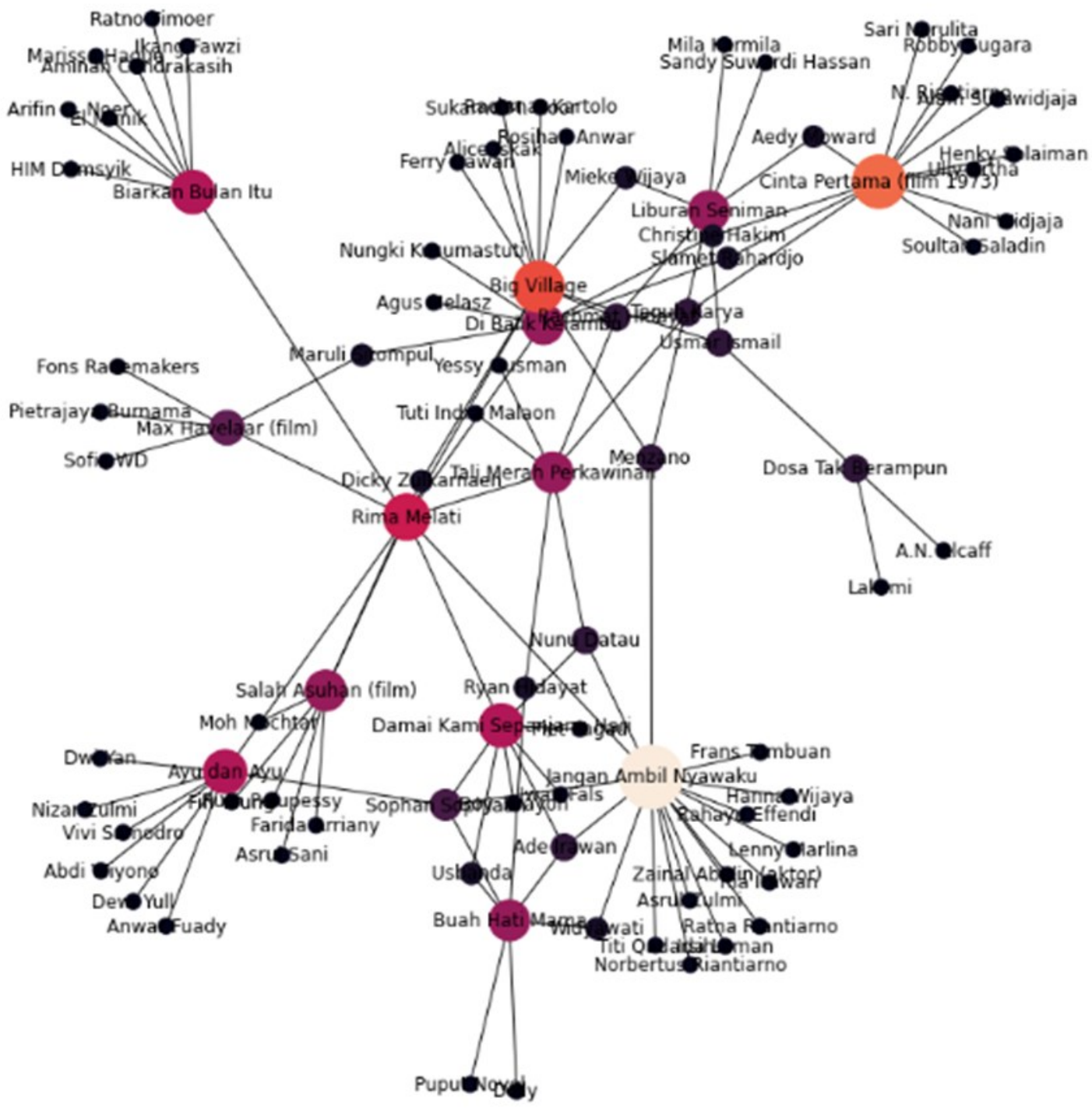

Gambar 11. Visualisasi dengan Density Graph 


\section{DAFTAR PUSTAKA}

[1] A. Nurwahdah, "Sistem Tanya Jawab dengan Web Semantik," in Seminar Nasional Aplikasi Teknologi Informasi (SNATI), 2015, vol. 1, no. 1.

[2] Y. F. Badron, F. Agus, and H. R. Hatta, "STUDI TENTANG PEMODELAN ONTOLOGI WEB SEMANTIK DAN PROSPEK PENERAPAN PADA BIBLIOGRAFI ARTIKEL JURNAL ILMIAH," in Prosiding SAKTI (Seminar IImu Komputer dan Teknologi Informasi), 2017, vol. 2, no. 1, pp. 164-169.

[3] A. Rochiyat and A. Wibowo, "Analisis Aktor Berpengaruh Dan Aktor Popular Dengan Metode Degree Centrality Dan Follower Rank Pada Tagar Twitter '\# gejayanmemanggil,"” JATISI (Jurnal Tek. Inform. dan Sist. Informasi), vol. 6, no. 2, pp. 130-138, 2020.

[4] M. S. Setatama and D. Tricahyono, “Implementasi Social Network Analysis pada Penyebaran Country Branding 'Wonderful Indonesia,"' Indones. J. Comput., vol. 2, no. 2, pp. 91-104, 2017.

[5] J. B. Sanawi, M. C. Samani, and M. Taibi, “\# vaccination: Identifying influencers in the vaccination discussion on twitter through social network visualisation," Int. J. Bus. Soc., vol. 18, no. S4, pp. 718-726, 2017.

[6] I. Gialampoukidis, G. Kalpakis, T. Tsikrika, S. Papadopoulos, S. Vrochidis, and I. Kompatsiaris, "Detection of terrorism-related twitter communities using centrality scores," in Proceedings of the 2nd International Workshop on Multimedia Forensics and Security, 2017, pp. 21-25.

[7] R. Oktora and A. Alamsyah, "Pola Interaksi dan Aktor yang Paling Berperan pada Event JGTC 2013 melalui Media Sosial Twitter (Studi Menggunakan Metode Social Network Analysis)," J. Manaj. Indones., vol. 14, no. 3, pp. 201-209, 2014.
[8] The W3C SPARQL Working Group, "SPARQL 1.1 Overview. W3C Recommendation 21 March 2013," W3C, 2013. .

[9] A. Grover and J. Leskovec, "node2vec: Scalable feature learning for networks," in Proceedings of the 22nd ACM SIGKDD international conference on Knowledge discovery and data mining, 2016, pp. 855864.

[10] M. Needham and A. E. Hodler, Graph Algorithms: Practical Examples in Apache Spark and Neo4j. O’Reilly Media, 2019.

[11] R. kumar Kaliyar, "Graph databases: A survey," in International Conference on Computing, Communication \& Automation, 2015, pp. 785-790.

[12] A. Hagberg, P. Swart, and D. S Chult, "Exploring network structure, dynamics, and function using NetworkX," Los Alamos National Lab.(LANL), Los Alamos, NM (United States), 2008.

[13] L. van der Maaten and G. Hinton, "Visualizing data using t-SNE," J. Mach. Learn. Res., vol. 9, no. Nov, pp. 2579-2605, 2008.

[14] N. Tatti, "Density-friendly graph decomposition," ACM Trans. Knowl. Discov. from Data, vol. 13, no. 5, pp. 1-29, 2019.

[15] “Daftar Film Indonesia." http:// id.dbpedia.org/page/Daftar_film_Indonesia.

[16] novyantsp, "novyantsp/notebook-tweb: Notebook Tweb," May 2020, doi: 10.5281/ ZENOD0.3839044. 


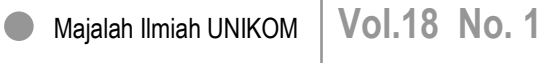

